\title{
NOTAS SOBRE ASPECTOS GRAMATICAIS DE ORDEM COGNITIVA E DISCURSIVA
}

Francimeire Cesário de Oliveira ${ }^{1}$

Rosângela Maria Bessa Vidal ${ }^{2}$

Telma Patrícia Nunes Chagas Almeida ${ }^{3}$

\begin{abstract}
RESUMO
Procuramos desenvolver uma discussão sobre a relação que a linguística funcionalista mantém com a linguística cognitiva, inclusive, a ela aliando-se para constituir um paradigma linguístico denominado de cognitivo-funcional, cuja pauta de investigação se empenha em estudar a língua em uso, ainda buscamos demonstrar aproximações entre os paradigmas que compõem a perspectiva cognitivo-funcional. Em seguida, tratamos de expor uma concepção de gramática centrada no uso que é entendida como um conjunto de regularidades que são convencionalizadas pelo uso concreto nas diferentes situações discursivas. As questões de análise envolvem o discurso e a interpretação das estruturas linguísticas, considerando o seu funcionamento, nas quais, analisamos indícios de eventos icônicos em textos do gênero tira em quadrinhos, corroborando indicativos relativos às questões elencadas pelo viés cognitivo-funcional. Como apontamentos finais destacamos dois itens provenientes das análises que demonstram motivações icônicas, quais sejam: a quantidade informações implica na codificação morfossintática e a organização sintática tem relação motivada pela ordem temporal dos fatos e pelas experiências do locutor.
\end{abstract}

Palavras-chave: Língua em uso. Gramática. Motivações icônicas. Cognitivofuncional. 


\section{INTRODUÇÃO}

Tomando por base as vinculações que podemos proceder entre áreas afins do conhecimento, o espaço teórico do funcionalismo linguístico não se isola de outros campos do conhecimento. Um bom exemplo é a aproximação da linguística funcional com a proposta do cognitivismo, que recebeu a denominação de linguística cognitivo-funcional. Intrínsecas ao perfil cognitivo-funcional são questões como o interesse em estudar a língua em uso, análises envolvendo o discurso e explicação das estruturas linguísticas a partir do seu funcionamento.

Nesse sentido, o desenvolvimento da linguística cognitiva é relativamente recente, com instalação nos anos de 1970, sendo enfatizada na década de 1980. O surgimento dessa nova área de estudos linguísticos dá-se no interior da tradição formalista. A ampliação de análises que apresentam como suporte a concepção cognitivista da linguagem pode ser encontrado em trabalhos clássicos como os de Fillmore e de Lakoff (FILLMORE,1977; LAKOFF, 1977), ou, ainda, em textos como os de Jackendoff (1992), Talmy (1988), Lakoff (1987) e Fillmore (1988).

A ligação do funcionalismo com a linguística cognitiva dá-se em razão de afinidades teóricas realçadas por questões como experiência, percepção e conceptualização do mundo, que envolvem aspectos cognitivos. Esse modo de olhar o fenômeno linguístico considera como básico o entrelaçamento entre conhecimento linguístico e conhecimento de mundo. O funcionalismo linguístico contemporâneo, como outras linhas de análise, acata a base cognitivo-funcional por ter em seu núcleo de discussão o interesse em estudar a natureza da linguagem a partir da língua em uso, cujo objeto de análise é o texto. Outros aspectos que funcionam como elementos convergentes para a ligação entre essas abordagens têm a ver com o movimento incessante da língua que se adapta ao contexto comunicativo, mediante as intenções do falante, o que implica dizer que a língua está em contínuo deslocamento.

Compatível com as noções que expressam a virtualidade da escola funcionalista, a base cognitivo-funcional passa a integrar a pesquisa que investiga a natureza da linguagem como um fenômeno que está continuamente a se renovar, em interface com os processos mentais e com os aspectos de ordem cultural. $O$ conjunto desses princípios teóricos enfatiza que a "linguagem, longe de ser um conhecimento fechado, [...] constitui o reflexo de processos gerais de pensamento 
que os indivíduos elaboram ao criarem significados, adaptando-os a diferentes situações de interação com outros indivíduos (WILSON; MARTELOTTA, 2009, p. 77).

Para delinear um perfil da linguística cognitivo-funcional, cabe citar a contribuição de Ronald Langacker (1987), George Lakoff (1987), pesquisadores que foram adeptos do gerativismo, como também o trabalho de psicolinguistas como Michael Tomasello (1999) e John Taylor (1995). Com uma existência ainda muito recente, a linguística cognitivo-funcional apresenta a proposta de integrar em suas análises os dados sociais e cognitivos. Em outras palavras, o que se pleiteia é uma formulação do fenômeno linguístico, considerando os usos que são efetivados pelos falantes na interação, como também a questão cognitiva na construção do significado.

Tomasello (1999) explicita a articulação entre a linguística funcional e a cognitiva ressaltando que a linguística, para produzir uma descrição satisfatória, necessita buscar junto à cognição subsídios para explicar questões como compreensão, processamento e aquisição da linguagem. A explanação cognitivofuncional surge principalmente do entendimento de que "cada entidade linguística é definida com relação à função a que serve no processo real de comunicação linguística" (TOMASELLO, 1999, p. 1). Sob a perspectiva cognitivo-funcional, o fenômeno linguístico passa a ser analisado considerando o uso como elemento norteador das investigações, isto é, a pesquisa tem o uso linguístico como base e apoio.

A partir do uso constituído pela interação, dá-se o processo de comunicação, e é por intermédio da língua que se tem acesso à informação, que se expressam e defendem pontos de vista, que se partilham e constroem visões de mundo, que se produz cultura, fazendo a mediação das atividades dialógicas e representando o conjunto dessas, disponíveis no funcionamento da linguagem e na comunicação de uma sociedade.

É de suma relevância destacar que o conceito de comunicação não se reduz à codificação e à transmissão de informação, mas abrange todos os aspectos envolvidos no evento de fala. Por isso, a língua em uso notabiliza um vínculo com a competência comunicativa e não apenas com a competência linguística em si. 
Nesse sentido, é ao considerar o nível discursivo e cognitivo, além do nível pragmático, que se consegue traduzir aspectos manifestos no plano comunicativo da linguagem.

Tal compreensão decorre de a língua ser vista como prospecto de significados e sentidos delineados pela interação complexa de princípios cognitivos e funcionais capazes de motivar variações e mudanças no sistema linguístico.

Para dar direção à dinâmica deste trabalho apresentamos seu percurso, que num primeiro momento, busca descrever como se dá o liame entre essas duas linhas da linguística em pauta, enumerando que aspectos evidenciam suas identificações e suas aproximações, além de evidenciar alguns contornos em que se emolduram a perspectiva cognitivo-funcional. Em seguida, tratamos de expor uma concepção de gramática centrada no uso. Isso posto, algumas realizações desses eventos serão analisadas em textos do gênero tira em quadrinhos, pelo viés cognitivo-funcional, nos quais demonstramos como as motivações implicam na codificação morfossintática. Por fim, apontamos algumas considerações que resultaram das observações empírico-teóricas das análises.

\section{NOTAS E DESCRIÇÕES GERAIS}

Os estudos da linguística cognitivo-funcional entendem que as formas linguísticas e sua aparente regularidade, bem como a instabilidade inexorável assumem funções decorrentes do processo sociocomunicativo, sendo suscetíveis a mudanças e variações linguísticas. Procura, desse modo, descrever e explicar os fatos linguísticos com base nas funções (semântico-cognitivas e discursivopragmáticas) que desempenham nos diversos contextos de uso da língua.

Nessa concepção, a gramática é compreendida como representação cognitiva da experiência dos indivíduos com a linguagem, por isso, ela pode ser afetada pelo uso da língua. Em outros termos, o falante não desenvolve arbitrariamente o uso da língua.

Esses pressupostos revelam uma associação intensa entre conhecimento, experiência de mundo e modo de organização das formas linguísticas, no sentido de que o conjunto de vivências de uma comunidade contribui para construção dos padrões gramaticais ou estruturais da língua. 
$\mathrm{Na}$ regularização do uso, outros aspectos se integram ao processo como as motivações, tanto de natureza discursiva como de natureza cognitiva, concernentes aos processos mentais envolvidos no uso linguístico durante a interação. Assim, a relação entre cognição e linguagem se evidencia, e o funcionalismo linguístico não se isenta de incluí-la, pois há vínculos cognitivos na constituição de itens linguísticos estruturais.

Segundo Furtado da Cunha (2012, p. 33) a explicação para a existência dos padrões de regularização da língua deve ser procurada no âmbito da cognição e da comunicação, para tanto a autora se vale do conceito de universais linguísticos, conceito que neste estudo é compreendido como sendo constituído por propriedades afins que todas as línguas manifestam,

a busca pelos universais deve focalizar os processos que criam e mantêm as estruturas linguísticas, e não as próprias estruturas. Sendo a língua um sistema simbólico por excelência, utilizado para comunicar informação sobre o mundo, naturalmente ela reflete essas conceitualizações.

Por esse viés, há trajetórias universais de gramaticalização que levam à formação de novas construções gramaticais.

De acordo com esse enfoque, faz-se necessário ampliar o entendimento possibilitado pela Linguística Cognitiva, cuja referência faz menção ao movimento gerativista. Esse debatia a linguagem tendo como princípios básicos o inatismo e a autonomia do conhecimento. Nessa abordagem, o cérebro tinha uma ação depositária e a estrutura gramatical era postulada como decorrente do princípio inatista. A linguagem era vista como separada da cognição, localizada em um módulo independente, o que era chamado de princípio da modularidade. Tal visão embasou a soberania da sintaxe, visto que cada módulo respondia separadamente por partes específicas do conhecimento.

Essa compreensão colaborou para o entendimento de como a mente humana interage com o mundo, além de explicar como os elementos que atravessam essa interação se constituem. A ideia base do movimento gerativista é a busca por aspectos linguísticos universais e, para tal, considera o interlocutor como algo idealizado, como membro de uma comunidade linguística ideal. Por conta disso, não reconhece os eventos sociais e o modo interativo de conceber a linguagem, como também, o uso corrente da língua. 
Os pressupostos gerativistas foram questionados por linguistas como George Lakoff e Charles Filmore, que incorporam o componente semântico na análise da língua, desmobilizando a autonomia sintática proposta pelos gerativistas.

Conforme Martelotta (2009, p. 178-9), a crítica mais ferrenha ao gerativismo não é quanto ao inatismo, porque realmente os seres humanos nascem com aptidões inatas que os estimulam a aprender, de modo que não se pode distinguir rigidamente entre o que é inato e o que é aprendido. A crítica se volta para o fato de essas habilidades serem específicas da linguagem.

É sabido que a mente não constrói a linguagem de maneira assistemática, pois na articulação entre linguagem, pensamento e experiência há a subsistência de conhecimentos linguísticos e não linguísticos. Assim, ao invés de funcionar em separado, as estruturas linguísticas se materializam socialmente e não corporificam apenas o funcionamento da mente dos indivíduos, mas os rituais de procedência cultural também.

Essa circunstância fica mais visível com a consideração da noção de contexto, cujo relevo se mostra nos arranjos múltiplos e dinâmicos da significação, fracassando no plano das significações prontas, que nessa visão estão sempre em construção. Mas como se comunicar com fundamento na instabilidade?

Isso é possível porque há um sistema regulador de significações que se monta no processo de categorização da realidade e simultaneamente se desmonta pelo complexo de inferências contextuais advindas dessa mesma realidade. Essa espécie de conflito que se instala no sistema é porque a realidade se modifica a cada instante, procedendo-se assim a incidência de pontos de vistas plurais. Sobrevém disso que os significados e o fluxo de sentidos não são elementos de exclusividade da mente, eles se integram a outros domínios, ou seja, como "resultado de uma atividade conjunta - associada a operações de projeção e transferência entre domínios." (MARTELOTTA, 2009, p. 180).

Nessa linha de pensamento, os processos mentais possibilitam a produção de significações, assinalando-se, entretanto, que a linguagem não é um processo automático da mente, ou como diz Neves (1997, p. 3), inspirada em Givón (1995), as interpretações se articulam não podendo ser emitidas "sem referência a parâmetros como cognição e comunicação, processamento mental, interação social e cultura, mudança e variação, aquisição e evolução." 
Essa concepção vem ressaltar a não arbitrariedade e invariabilidade desse sistema "pronto", como também, endossá-lo como provisório, o que incita mudanças, dada a criatividade e a capacidade do homem inovar. São inovações decorridas do discurso, que faz ponte com as referências cognitivas do mundo.

Nesse sentido, o uso da língua é constituído por uma significação, que busca a coexistência de um interlocutor real, no trato das dimensões orais e escritas, e faz uso de instrumentos que possibilitam o seu funcionamento.

Por essa visão, as sentenças dão vida aos enunciados, que podem ser analisados e entendidos levando-se em conta as motivações cognitivo-discursivas, isto é, a estrutura sintática é visualizada como resultante de componentes discursivos e de experiências cognitivas.

\section{CONCEPÇÃO DE GRAMÁTICA}

A gramática, nessa ótica, é concebida como um conjunto de regularidades que são convencionalizadas pelo uso concreto nas diferentes situações discursivas.

Contudo, é válido frisar que as construções linguísticas que são evocadas no uso, não passam de imediato a fazer parte do sistema gramatical. Para isso, passam por um contínuo de mudanças linguísticas, como diz Bolinger (1975, apud MARTELOTTA, 2003), elas precisam ser percebidas, apreciadas para serem adotadas e, mesmo assim, ainda não se estabilizam, isto é, "as mudanças de uma língua devem ser compreendidas como movimentos que se iniciam no instante que um indivíduo produz seu discurso [...]." (MARTELOTTA, 2003, p. 71).

Essas mudanças estão em conformidade também com o conceito de ciclo funcional, formulado por Givón (1979), referindo-se a esses estágios que circundam o contínuo de mudanças, por ele elencados nessa ordem: discurso > sintaxe > morfologia > morfofonologia > zero.

Já Hopper (1991, apud OLIVEIRA; VOTRE, 2009) adota outra terminologia para categorizar os estágios de mudança linguística que é a persistência (manutenção de traços da forma fonte) e divergência (perda de marcas semânticosintáticas em relação à forma fonte), ambas mediadas pelo processo de metáforas.

Uma tese mais radical quanto à concepção de gramática é a proposta de Hopper (1987) que defende sua constituição com referência excepcional no plano discursivo, tese também aceita por Bolinger em 1977 e Dubois em 1985, nesse 
sentido, "a gramática é entendida como instância marcada pela maleabilidade e instabilidade, as classes são fluidas, de contornos poucos precisos, com destaque para os fenômenos de derivação de sentido e de mudança categorial." (OLIVEIRA; VOTRE, 2009 p. 99).

A concepção de gramática que Paul Hopper defendeu em 1987, e retomou em 1998, a que chamou de "gramática emergente" tem como propósito central contestar o pressuposto de que as línguas são ajustadas por estruturas organizadas em regras sistemáticas, previamente disponíveis e anteriores ao processo de aquisição e desenvolvimento de uma língua. Na essência, Hopper recusa a ideia de língua como um sistema abstrato, fixo, sustentado por um conjunto fechado de regras, que deixe a descoberto ocorrências desviantes.

Essa concepção é fundamentada pelos usos discursivos, além de propor uma formação cognitiva norteada pelas experiências que cada sujeito falante opera nas suas ações discursivas. Dessa maneira, um falante, ao exercer a atividade de falar, aciona mecanismos cognitivos que não são postulados como sendo estruturas fixas, mas sim como experiências materializadas em construções, usadas por interlocutores e submetidas às subjetividades do contexto interativo.

Sendo assim, os aspectos linguísticos se adaptam às necessidades de comunicação dos falantes e as gramáticas refletem essas adaptações, ou seja, a forma da língua deve ser compatível com a função que desempenha. A codificação das estruturas morfológicas e sintáticas, segundo as autoras citadas a seguir, se edificam tendo como alicerce as estratégias cognitivo-discursivas, ressaltando-se ainda que "há um forte vínculo entre discurso e gramática, de tal modo que a morfossintaxe tem sua origem no discurso." (FURTADO DA CUNHA; TAVARES, 2007 p. 34).

É nessa intensa relação entre discurso e gramática, que se visualizam as forças em competição na língua, por um lado, uma que dá acesso às novas construções e aos novos usos e, por outro, uma que limita e regula o sistema. Temse em vista, portanto, o entendimento de que a gramática dá corpo ao discurso e o discurso influencia o corpo gramatical e que os processos comunicativos e cognitivos motivam a constituição das estruturas gramaticais.

Assim, o falante organiza e participa de situações comunicativas com base no que está em sua mente, que é influenciada pelo que ocorre na esfera do contexto de 
interação. Infere-se, assim, que a gramática deve ser estruturada a partir do uso com a expectativa de atender à realidade experiencial dos usuários da língua.

Esse viés se complementa com o pressuposto da integração dos componentes linguísticos, cuja ênfase se volta para o modo pragmático sob a alegação de que a partir das regularidades nele observadas é possível sistematizar, mesmo que provisoriamente, a gramática do uso, além de encaminhar mecanismos de seleção, organização e atualização dos padrões incorporados à gramática.

Por esse encaminhamento, resgatam-se aspectos do uso inerentes à situação comunicativa como as intenções e o perfil do usuário, a condição social, o grau de informatividade e uma gama de fatores histórico-sociais que conduzem o uso da língua, dando-lhe suporte, e, apoio para a análise textos em circulação, sendo a gramática funcionalista a base que acolhe essa compreensão.

A respeito da visão integrada dos componentes linguísticos, Neves (1997) faz referência ao pensamento de Givón (1984). Este reconhece a necessária relevância de se esclarecer, de forma explícita, sistemática e abrangente, a congregação desses componentes, tendo em vista que a gramática não é um depósito que armazena os domínios funcionais da língua, como se fossem caixotes e cada um deles, isoladamente, pudesse comportar traços desses domínios. O autor compara a gramática com um organismo que subdivide sua estrutura interna em subsistemas inter-relacionados para exercer suas funções de modo organizado, obedecendo a um nível hierárquico.

Do ponto de vista hierárquico, a sintaxe é responsável por codificar os sistemas funcionais: a semântica (proposicional) e a pragmática (discursiva). Sucede que uma estrutura codificada deve ser submetida à função semântica e pragmática, simultaneamente, do contrário, não é possível haver comunicação. Em outras palavras, a interdependência entre os componentes é crucial, pois o ato efetivo da comunicação está pragmaticamente situado e se vale de arranjos sintáticos para ganhar sentido. Enfim, resume-se que não se admite nesse paradigma a existência de uma sintaxe autônoma.

A presente abordagem enfatiza a presença do discurso e de suas múltiplas facetas para tornar os enunciados passíveis de análise e reflexão, sendo coerentes com os eventos comunicativos de que fazem parte. E, para reforçar esse pensamento, é importante reproduzir o que Du Bois (1985) assegura quando afirma que "as relações entre discurso, ou uso, e gramática assim se equacionam: [...] 'a 
gramática é feita à imagem do discurso'; mas: 'o discurso nunca é observado sem a roupagem da gramática"' (NEVES, 1997, p. 29).

A tênue linha divisória entre os componentes, do sintático ao semântico e ao pragmático, demonstra a intimidade fronteiriça entre discurso e gramática.

Por extensão, se apresenta a relação entre gramática e cognição, que acontece face aos vínculos destas com as experiências humanas. Nesse sentido, uma teoria da gramática deve aliar categorias linguísticas e categorias cognitivas, dando condições à emergência de um sistema icônico não arbitrário, o que implica uma base conceptual para a gramática, cujos fundamentos buscam referências em categorias da Linguística Cognitiva.

Nesse raciocínio, as categorias linguísticas circundam um eixo que pode ter um centro e categorias periféricas, sendo estas pressionadas pelo centro e por uma forma gravitacional (natural). Servem como fluxo para a formação de novos centros, embora com menos força expressiva no seu teor sintático-semântico, mas com dinamicidade pragmática, porque passam a assimilar com mais intensidade aspectos oriundos das relações interpessoais.

Em tal cenário, as motivações gramaticais, como as que alteram os padrões de ordenação e de funcionalidade de determinados constituintes gramaticais no discurso, conferem fluidez ao sistema. As construções linguísticas podem se mover de uma categoria para outra, pois a situação comunicativa se responsabiliza por situar a forma, dando-Ihe uma significação apropriada, tornando-a adaptável e capaz de ser remoldada, porque ela se destina a atender aos propósitos das situações de uso. Esse fato revitaliza a gramática como procedimento necessário para organizar as esferas linguísticas de uso do discurso.

Segundo Martelotta (2009), tal concepção de gramática traz em seu bojo dois tipos de habilidades que norteiam as atividades verbais: a natureza sociointerativa e a natureza cognitivo-funcional. A primeira possibilita o compartilhamento de informações no contexto social, no qual não é necessário verbalizar todas as formas linguísticas de uma situação de comunicação, porque os interlocutores são capazes de apreender/introduzir, nos enunciados, elementos subjetivos, como as intenções que se relacionam com o contexto de ocorrência dos atos enunciativos.

Já a segunda integra-se à anterior e responde pelo modo como a informação é processada na mente. Implica a capacidade que o homem tem de analisar e interpretar os fatos e relacioná-los com o seu modo de atuar discursivamente. 
Há, então, a transferência de dados de um domínio para outro, ou seja, manifestam-se no discurso (elemento linguístico) as experiências sensório-motoras (aspectos cognitivos) através da metáfora espaço>discurso>texto.

Assim, a perspectiva cognitivo-funcional considera que o funcionamento da língua envolve aspectos definidos por teorias sociais, interacionistas e cognitivas. Os que por ela se pautam devem associá-la "a um fenômeno mais geral segundo o qual a experiência humana mais básica, que se estabelece a partir do corpo, fornece as bases de nossos sistemas conceptuais." (MARTELOTTA, 2009, p. 65).

De acordo com essa abordagem, a estrutura gramatical não pode ser destituída de significado, mas compactua com a visão integrada dos componentes da linguagem, da qual a compreensão mais acolhida é a de um contínuo representacional que direciona a estrutura conceptual para atender a fins comunicativos.

Martelotta (2009) destaca que um ponto relevante na Linguística Cognitiva é o caráter interacional da construção do significado, atuando como um divisor de águas no campo da linguagem, isso porque o gerativismo exclui da língua os fenômenos reais e comunicativos. Com a mudança de foco, os usuários da língua são agentes na construção do significado e levam em conta a compreensão dos dados da experiência. Sua perspectiva coaduna-se com uma concepção de gramática que vai muito além das regras e da competência linguística. Para os cognitivistas,

[...] a gramática de uma língua constitui um conjunto de princípios
dinâmicos, os quais, nas palavras do linguista Ronald Langacker, se
associam a rotinas cognitivas que são moldadas, mantidas e modificadas
pelo uso. Mais do que isso, para os cognitivistas, a comunicação é uma
atividade compartilhada, ou seja, implica uma série de movimentos feitos
em conjunto pelos interlocutores em direção à compreensão mútua. Isso
quer dizer que a significação é negociada pelos interlocutores em situações
contextuais específicas, o que torna possível que os elementos linguísticos
se adaptem às diferentes intenções comunicativas, apresentando flutuações
de sentido [...]. (MARTELOTTA, 2009, p. 181).

Portanto, na abordagem cognitivo-funcional encontra-se respaldo para dizer que a língua tem funções cognitivas e sociais. $O$ desempenho destas tem um papel central na produção das estruturas e dos sistemas que compõem a gramática de uma língua. Por essas estruturas não serem fechadas, representam continuadas regularidades que dão aparência de estabilidade. 
O reconhecimento de que a gramática não postula apenas estruturas arbitrárias é uma das consequências desse modo de refletir sobre a língua que leva em consideração a tese de que a gramática das línguas naturais é um conjunto de escolhas realizadas pelo falante, que para tanto vincula as estruturas às estratégias dos domínios discursivos e cognitivos.

\section{CODIFICAÇÕES MORFOSSINTÁTICAS DOS USOS LINGUÍSTICOS E SUA NATUREZA ICÔNICA}

Ao analisar a natureza icônica dos aspectos morfossintáticos apresentada nos textos, incluem-se na análise aspectos discursivos e cognitivos.

Nesse sentido, passamos a nos focar na Figura 1. Nesta, questões icônicas, como a quantidade de informação, atua como fonte de influência que leva à codificação das formas linguísticas.

Centrando-se nos enunciados pronunciados pelo segundo personagem (bruxa virtual) observemos que eles são linguisticamente condensados, o que responde a um apelo cognitivo, quanto ao processamento de informações de uma carga informativa que se apresenta menos densa na sequência textual.

\section{Figura 1}

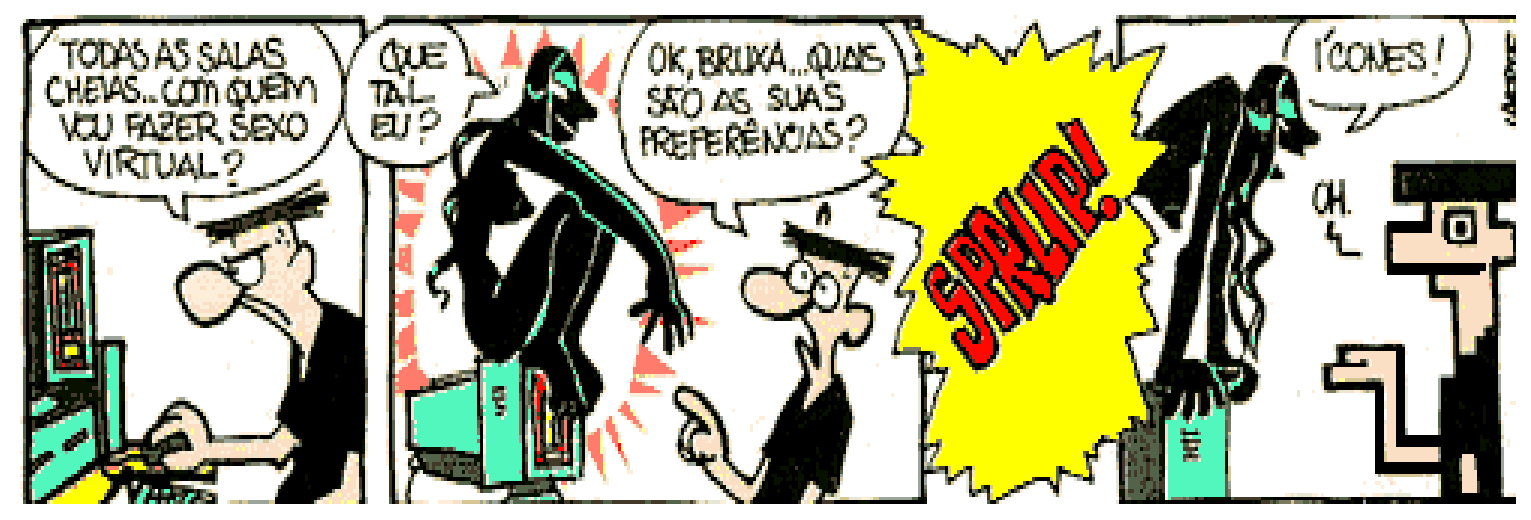

Fonte: www.laerte.com.br

Os enunciados são curtos e, cognitivamente, de fácil apreensão textual, mas há um teor informativo que o leitor deve construir, aferindo assim um contexto informativo mais expressivo. 
A escolha dos itens lexicais, que compõem o gênero em análise, serve de pista para encaminhar o leitor na descoberta dos significados pretendidos; essa escolha é sempre regulada pelo contexto de onde emanam as condições de produção e interpretação. Assim, a iconicidade dos itens lexicais será mais perceptível, se mais adequada for a sua seleção, isto é, como nesse gênero, há necessidade de ser expressivo, em poucas palavras, dadas as restrições do gênero, o processo das escolhas lexicais deve ser mais rigoroso ou eficiente.

No primeiro balão, o primeiro enunciado (“Todas as salas cheias...") é menos denso em quantidade de elementos do que o seguinte, por outro lado, requisita maior esforço cognitivo porque o verbo está implícito (estão), em contraposição, o segundo (“...com quem vou fazer sexo virtual?”) é expresso por um verbo perifrástico (vou fazer). No primeiro caso, trata-se de uma constatação, enquanto no segundo, a intenção é de lamentação porque o desejo demonstrado pelo personagem continua em processo, prenunciando os fatos posteriores, ou seja, indicando a sua continuidade.

Assim, a escolha entre um verbo não codificado morfossintaticamente e outro codificado, perifrasticamente, deixa evidente não só o acréscimo de formas linguísticas e maior quantidade de informação, mas atende também ao propósito comunicativo do evento textual desse gênero e mantém uma relação de proximidade e distanciamento (integração) entre os termos.

$\mathrm{Na}$ Figura 2, há uma relação icônica demonstrada através de uma sequência de fatos ou, neste caso, percepções. $01^{\circ}$ personagem percebe que o brinquedo virtual não está funcionando, depois vai enunciando supostas constatações (quebrou e sumiu), para então chegar à constatação final de que o 'bicho' (dinossauro) representado metonimicamente por sua pata - está fora do brinquedo.

\section{Figura 2}

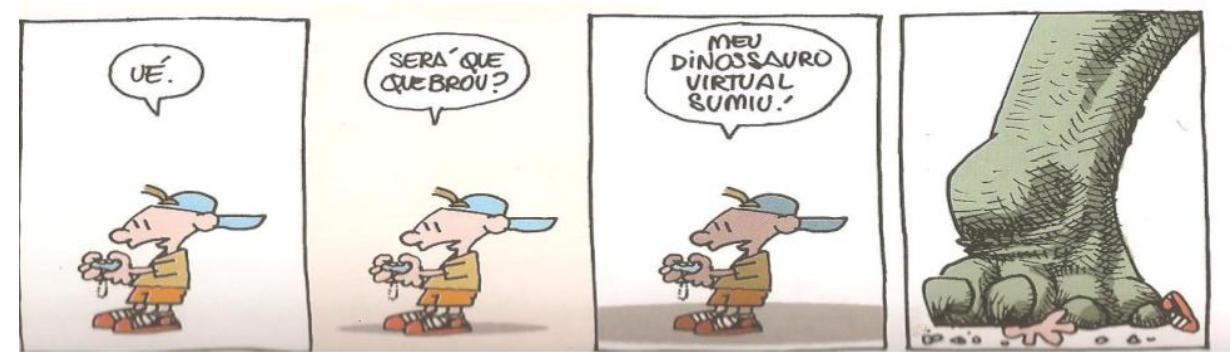

Fonte: www.laerte.com.br 
Os verbos utilizados no pretérito perfeito, tempo em que se exprimem processos verbais concluídos, situam esse evento como uma sequência de constatações e não de possibilidades.

A escolha por esse tempo verbal é recorrente nas tiras em quadrinhos que apresentam uma sequência de ações. Por se tratar de fato já acontecido, mesmo que a constatação se dê num tempo presente, a codificação é representada pelo pretérito-perfeito, como se pode ver no evento da Figura 3.

\section{Figura 3}

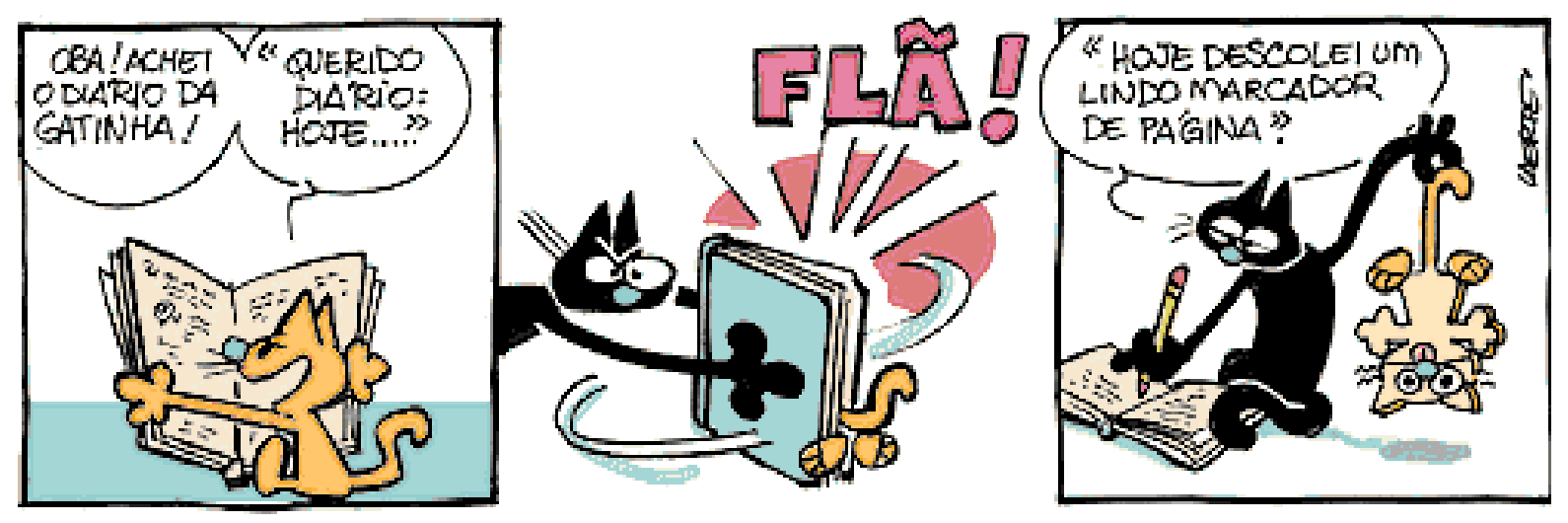

Fonte: www.laerte.com.br

O ordenamento sintático dos enunciados procura refletir a forma como os eventos estão organizados na mente do falante, o que evidencia uma relação intrínseca entre a sintaxe que se produz no uso da língua e a consistência cognitiva que orienta a experiência do interlocutor, ao estabelecer as relações entre o uso da língua e os fatos que compõem um processo complexo.

Nesse sentido, há uma forte tendência da complexidade cognitiva incidir em complexidade das expressões linguísticas. No caso, há uma sequência progressiva dos fatos, expressa por uma codificação morfossintática simples que, segue a ordem padrão (SVO), mas entre a codificação e sua significação é que se manifesta o grau de complexidade, pois é o locutor quem vai aferir o conteúdo relativo à produção de sentido. Assim, a complexidade não é evidenciada unicamente pela codificação morfossintática que apenas registra indícios para isso, como o ordenamento dos fatos retratado a pouco.

Desse modo, a organização sintática pode ser guiada pela ordem temporal dos acontecimentos, isto é, existe um nexo de motivação icônica nesse evento. Em 
suma, se pode reafirmar que a sintaxe não é uma entidade independente, pois é funcionalmente motivada por processos cognitivos e comunicacionais.

\section{APONTAMENTOS FINAIS}

Compreendemos, a partir da trajetória percorrida neste trabalho, que a língua, em qualquer perspectiva, seja na linha funcionalista ou na linha cognitiva, assume regularização no uso. Desse modo, essas duas linhas compartilham vários outros pressupostos, dentre eles a contiguidade entre a estrutura das línguas e o uso que os falantes fazem delas nos contextos reais de comunicação, a inclusão da semântica e da pragmática às análises, a ideia de que o conhecimento do mundo e o conhecimento linguístico seguem, essencialmente, os mesmos padrões. Portanto, esses pressupostos estão presentes na perspectiva cognitivo-funcional.

Assim sendo, a Linguística Cognitivo-Funcional postula que a regularidade da língua é provisória e que sua instabilidade é motivada pelas realizações discursivas dos usuários no cotidiano social. Além disso, apresenta respaldo teóricometodológico para asseverar que a língua tem funções cognitivas e que a gramática não postula apenas estruturas arbitrárias, mas também icônicas.

Quanto aos aspectos icônicos, pensamos ter demonstrado que o processamento das informações tem uma relação motivada com sua codificação, evidenciando sua face cognitiva e discursiva. Outro aspecto a salientar é que o ordenamento sintático dos enunciados procura refletir a forma como os eventos estão organizados na mente do falante, isto é, a ordem sintática é orientada pela ordem temporal dos acontecimentos.

\section{NOTAS}

\footnotetext{
${ }^{1}$ Prof ${ }^{a}$ Ms. Rede de Ensino da Educação Básica do Estado do Rio grande do Norte e da Rede Municipal de Ensino de Marcelino Vieira-RN.

2 Profa Dra. Universidade do Estado do Rio Grande do Norte (UERN) e do Programa de PósGraduação de Letras (PPGL), Campus de Pau dos Ferros-RN.

3 Mestranda do Programa de Pós-Graduação de Letras (PPGL). Bolsista FAPERN/CAPES, Universidade do Estado do Rio Grande do Norte (UERN).
} 


\title{
NOTES ON GRAMMATICAL ASPECTS OF COGNITIVE AND DISCURSIVE ORDER
}

\begin{abstract}
We seek to develop a discussion on the relationship that keeps the functionalist linguistics to cognitive linguistics, including her allying themselves to constitute a linguistic paradigm called cognitive-functional staff whose research strives to study the language in use, we are still looking demonstrate similarities between the paradigms that make up the cognitive-functional perspective. Then, we try to expose a design centered on the use of grammar which is understood as a set of regularities that are conventionalized by actual use in different discursive situations. The issues involve the speech analysis and interpretation of linguistic structures, considering their operation, in which we analyze evidence iconic events in texts of the genre comic strip, corroborating indications concerning matters listed by functional cognitive bias. As final notes include two items from our analysis show that iconic motivations, namely: quantity information implies the morphosyntactic encoding and syntactic organization is motivated by the relative temporal order of events and experiences of the speaker.
\end{abstract}

Keywords: language in use; grammar; iconic motivations, cognitive-functional.

\section{REFERÊNCIAS}

DU BOIS, J. W. Competing motivations. In: HAIMAN, J. (Ed.) Iconicity in syntax. Amsterdam/Philadelphia: J. Benjamins, 1985.

FILLMORE, C. Scenes-and-frames semantics. In: ZAMPOLLI, Antonio (Ed.). Linguistics structures processing: fundamental studies in computer science. Amsterdam: North-Holland, 1977.

FILLMORE, C.; KAY, P.; O'CONNOR, M. C. Regularity and idiomaticity in grammatical constructions: the case of Let Alone. Language, v. 64, p.501-538, 1988.

FURTADO DA CUNHA, M. A. A linguística centrada no uso (ou linguística cognitivofuncional). In: SOUZA, M. Medianeira et al. (Org.). Sintaxe em foco. Recife: PPGL / UFPE, 2012. p. 29-49. 
FURTADO DA CUNHA, Maria Angélica; TAVARES, Maria Alice (Orgs.).Linguística funcional e ensino de gramática.In.:

Natal-RN: EDUFRN, 2007. p. 13-52. Funcionalismo e ensino de gramática.

GIVÓN, Talmy. Syntax. Amsterdam: John Bejamins, 2001. v. 1.

. Functionalism and grammar. Amsterdam/Philadelphia: John Benjamins Publishing Company, 1995.

. On understanding grammar. New York: Academic Press, 1979.

HOPPER, P. J. Emergent grammar. Berkeley Linguistics Society, v. 13, p. 139-157, 1987.

JACKENDOFF, R. Languages of the mind. Cambridge, MA: MIT Press, 1992.

LAKOFF, G. Linguistics Gestalts. Chicago Linguistic Society, 1977.

Women, fire and dangerous things: what categories reveal about the mind.

Chicago: Chicago University Press, 1987.

LANGACKER, R. W. Foundations of cognitive grammar: theoretical prerequisites. Stanford: Stanford University Press, 1987. v. 1.

MARTELOTTA, Mário Eduardo. A mudança linguística. In: FURTADO DA CUNHA, M. A.; OLIVEIRA, M. R. de; MARTELOTTA, E. (Orgs.). Linguística funcional: teoria e prática. Rio de Janeiro: DP\&A, 2003. p. 57-71.

MARTELOTTA, M. E.; PALOMANES, R. Linguística cognitiva. In.: MARTELOTTA, M. E. et. al. Manual de linguística. São Paulo: Contexto, 2009.

NEVES, Maria Helena Moura de. A gramática funcional. São Paulo: Martins Fontes, 1997.

OLIVEIRA, Mariangela Rios de; VOTRE, S. J. A trajetória das concepções de discurso e de gramática na perspectiva funcionalista. Matraga, Rio de Janeiro, v. 16, n. 24, 2009.

TALMY, L. Force dynamics in language and cognition. Cognitive Science, v. 12(1), 1988.

TAYLOR, J. R. Linguistic categorization: prototypes in linguistic theory. Oxford: Clarendon Press, 1995.

TOMASELLO, M. (Ed.). The new psychology of language. New Jersey: Lawrence Erlbaun, 1999.

VIDAL, Rosângela M. B. As construções com advérbios em-mente: análise funcionalista e implicações para o ensino de língua materna. 2009. $188 \mathrm{f}$. Tese (Doutorado em Linguística Aplicada - Programa Pós-Graduação em Estudos da Linguagem)-Universidade Federal do Rio Grande do Norte, 2009. 
WILSON, V.; MARTELOTTA, M. E. Arbitrariedade e iconicidade. In: MARTELOTTA, Mário Eduardo (Org.). Manual de linguística. São Paulo: Contexto, 2009. p. 71-75. 